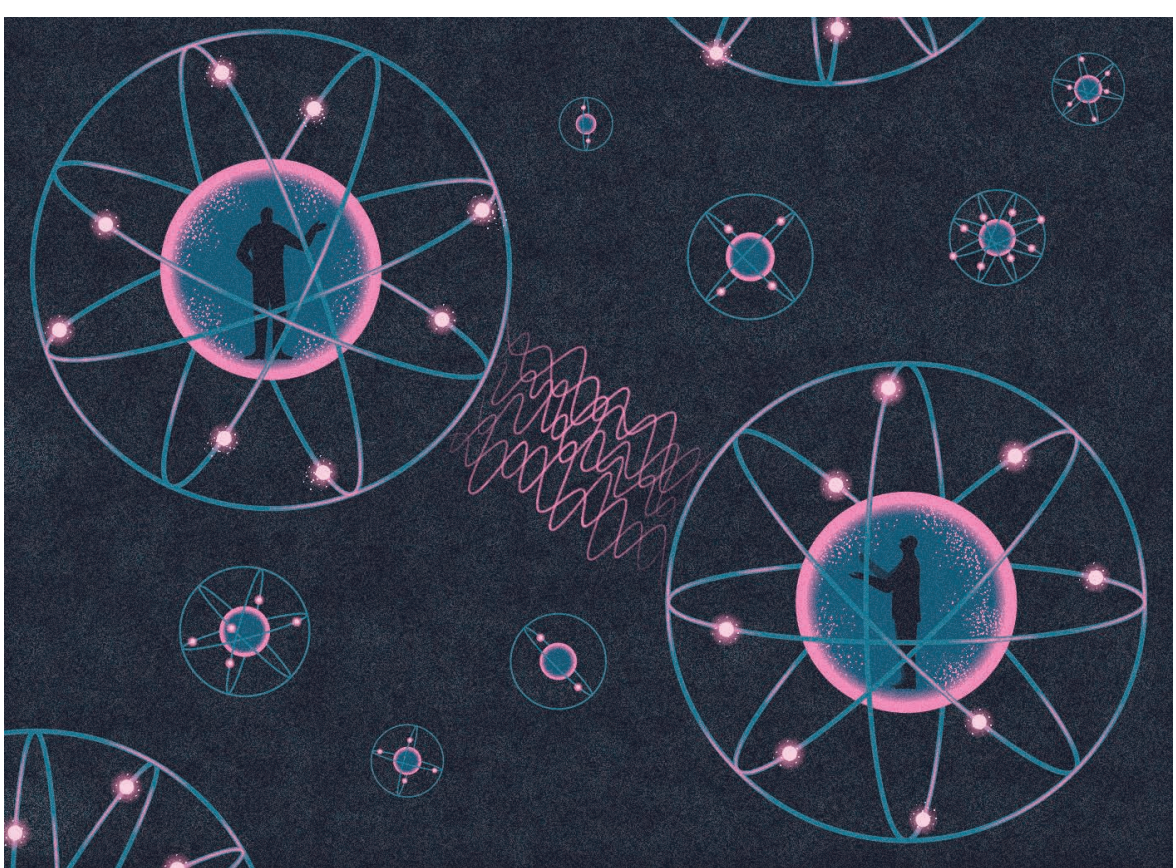

THEORETICAL PHYSICS

\section{When the doer met the dreamer}

\section{Graham Farmelo applauds a study on the productive friendship of two very different physicists.}

$\mathrm{R}$ ichard Feynman and John Wheeler, both consummate theoretical physicists, approached their subject in different ways. Feynman was a doer, Wheeler a dreamer. So Paul Halpern aptly describes them in The Quantum Labyrinth, his book about their lives, work and friendship, and the virtues of their complementary styles.

The two men met in 1939, probably in the physics department of Princeton University, New Jersey. Wheeler was then 28 , an assistant professor - quiet, measured and with impeccable manners. Feynman was seven years younger, a new and extremely promising $\mathrm{PhD}$ student and something of a rough diamond, raised in the borough of Queens, New York City. He became Wheeler's research assistant and they got on well, beginning what Halpern describes as "a long, productive - but often silly - friendship".

Amid all the larking around, Wheeler and Feynman did useful work. They came up with a new interpretation of the theory of moving electrically charged particles that yielded useful but not revolutionary results. Bursting with creativity, Feynman made his deepest contribution to physics while working alone. Picking up on a profound but under-developed idea by theoretician Paul Dirac, he found a way of reformulating quantum mechanics in terms of a 'sum

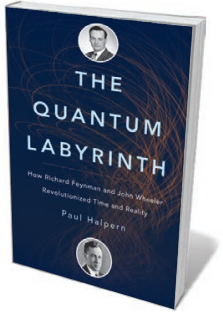

The Quantum Labyrinth: How

Richard Feynman and John Wheeler Revolutionized Time and Reality PAUL HALPERN Basic: 2017. method baffling. (They still do.)

Building on this success, Feynman came up with an ingenious way of doing calculations about the interactions of subatomic particles using what are now universally known as Feynman diagrams. They, too, were soon essential to the toolkit of particle physicists.

Although Feynman was not short of selfregard, he readily acknowledged his debt to Wheeler: "You might say that my success was a result of things I learned from him." Wheeler was even more generous: "I am eternally grateful for the fortune that brought us together." Wheeler's own accomplishments, which Halpern does a good job of highlighting, included a brilliant insight into the fission of uranium nuclei, conceived with the great Danish scientist Niels Bohr. This advance was fundamental to the development of nuclear weapons in the Manhattan Project, which drew in both Wheeler and Feynman. After the Second World War, Feynman dropped military-related work, unlike Wheeler, a nuclear hawk.

Although Wheeler was superficially stolid, he had an imagination arguably even more vivid than Feynman's. During the renaissance of gravity theory, beginning in the 1950s, Wheeler was perhaps its most energetic intellectual leader, willing to entertain even the most adventurous ideas. He enthusiastically supported research into black holes (a term he successfully promoted) and coined the word 'wormhole' to describe hypothetical tunnels in space-time.

Later, Wheeler was no less imaginative in

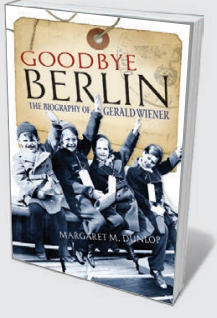

Goodbye Berlin: The Biography of Gerald Wiener Margaret M. Dunlop (Birlinn, 2017)

This fascinating biography of animal geneticist Gerald Wiener by writer Margaret Dunlop, his wife, describes Wiener's journey from his arrival in Britain on the Kindertransport during the Second World War to his pioneering research working with the team that cloned Dolly the sheep.

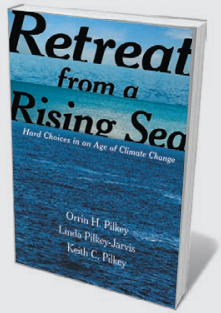

Retreat from a Rising Sea

Orrin H. Pilkey, Linda Pilkey-Jarvis and Keith C. Pilkey (Columbia Univ. Press, 2017) Science and policy intertwine in this cogent study of global sea-level change and the challenges of addressing it - from Alaskan villages forced inland from the coast to the ongoing surge of climate-change denialism. 
his thinking about information theory. He believed that information is not a secondary concept, but fundamental to the Universe. He coined the shorthand "it from bit" for the concept that every entity - every particle, every field and even space-time - derives its meaning from ideas in information theory. His view is now becoming part of the physics orthodoxy. In later life, Feynman told his colleague Kip Thorne that if you "unwrap the layers of craziness" from Wheeler's ideas, "you will often find a powerful kernel of truth".

Halpern admires Wheeler and Feynman so much that the narrative is occasionally cloying. As usual, Feynman is portrayed as a popular and generous-spirited figure. Yet I have often heard that he was sometimes unpleasantly aggressive to physicists who might claim to be his peers, several of whom have told me privately that they didn't much like him. Freeman Dyson is an exception to this, although even he told me: "Conversations with Feynman were mostly all about him."

At first, I doubted the depth of Feynman and Wheeler's friendship, but Halpern eventually convinced me. In one delightful passage near the end of the book, he describes a conference organized by Wheeler and held in Austin, Texas, in 1981 at a venue much too "fancy-schmanzy" for Feynman, as Halpern puts it. Feynman checked out of the room and slept in nearby woods, even though he was in remission from cancer. After one night of al fresco slumber, Wheeler invited him to stay in his home. Shortly afterwards, Feynman told a local reporter: "One of the biggest regrets of my life is that I am not as nice as [Wheeler] is." Feynman died 7 years later; Wheeler outlived him by 20 years.

The Quantum Labyrinth confirms the received opinion that Feynman was one of the greatest intuitive problem-solvers in twentieth-century physics, a world-class doer. But I suspect that many readers will take most pleasure from the account of Wheeler's inspired dreaming. As Dyson told me: "Posterity has given Feynman his due, but Wheeler has been cruelly underrated."

Graham Farmelo is a fellow of Churchill College at the University of Cambridge, UK, and author of The Strangest Man.

e-mail:graham@grahamfarmelo.com

\section{TECHNOLOGY}

\section{Into cyberia}

\section{Li Gong weighs up three tomes on Silicon Valley's vast influence, for good or ill.}

$\mathrm{T}$ The phrase "Making the world a better place" famously sums up the stated aim of Silicon Valley. Three books on California's digital kingdom and its 'four horsemen' (Amazon, Apple, Facebook and Google) see that as at best self-delusional. Their authors characterize the 'valley boys', their companies and, by extension, the technology industry and all of computer science as destroying the United States by eliminating jobs and polluting people's minds even enabling Donald Trump's presidency. Is Silicon Valley guilty as charged?

The Four, by marketing scholar Scott Galloway, is full of sharp insights and unconventional views. (Colourful asides include an account of his stint on the board of The New York Times as an activist shareholder, and a no-holds-barred career guide.) Instead of the usual rehash of product innovations or the personal peculiarities of valley players, Galloway analyses the big four's business context and competitive landscape, and clinically pinpoints differentiators of success that may surprise many. Apple stores, not the iPhone, transformed the company into a luxury brand - even as it enjoys a spectacular sales margin by maintaining its low-cost production base. Galloway's own proposals for success include a "T-algorithm" of eight factors (such as geographical location) for evaluating a company's prospects of becoming a trillion-dollar enterprise.

Galloway's main criticism of the tech
The Four: The Hidden DNA of Amazon, Apple, Facebook, and Google

SCOTT GALLOWAY

Portfolio: 2017.

World Without Mind: The Existential Threat of Big Tech

FRANKLIN FOER

Penguin: 2017.

The Know-It-Alls: The Rise of Silicon Valley as a Political Powerhouse and Social

Wrecking Ball

NOAM COHEN

The New Press: 2017.

industry is its impact on non-tech jobs. He suspects that Amazon head Jeff Bezos supports a guaranteed income in the United States because he looks at the future and does not see many humans in jobs. Amazon's warehouses and data centres are exhibit A in a robotics heaven. Galloway brusquely calls on "Jeff" to show some real vision.

In World With out Mind, journalist Franklin Foer argues that the tech industry has had a negative impact on knowledge and democracy, by controlling information flow. He sees tech as an existential threat. He focuses on its role in the decline of journalism and creative writing, drawing on his stint as editor-in-chief of New Republic. In 2012, Facebook co-founder Chris Hughes bought the magazine to rebrand it as a digital-media company, prompting a staff exodus. Foer was given a monthly

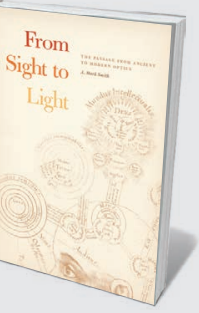

From Sight to Light

A. Mark Smith (Univ. Chicago Press, 2017) Historian Mark Smith unpicks optics from the classical period on. He pinpoints Johannes Kepler's seventeenth-century research on retinal imaging as the shift towards modern optics, along with René Descartes's study of refraction and the development of instrumentation.

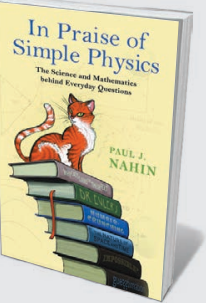

In Praise of Simple Physics: The Science and Mathematics behind Everyday Questions Paul J. Nahin (Princeton Univ. Press, 2017) The energy of moving water, the physics of communication satellites and the maths behind catching a ball are all skilfully dissected by engineer and writer Paul Nahin in this enjoyable study of everyday physics. 